\title{
Agriculture and Agri-Food Canada's research program on antimicrobial resistance
}

\author{
E Topp ${ }^{1 *}$
}

\begin{abstract}
A key strategy for attenuating the development of antimicrobial resistance (AMR) is ensuring judicious use of antimicrobials in human and veterinary medicine and in agriculture. Research on AMR in agriculture includes risk assessment, risk management, and identifying the role of agricultural practices in development of AMR. Risk assessment includes an impact assessment of antimicrobial use in livestock and on the environment; for example, many antimicrobials are excreted unchanged and thus reach the environment through manure application. This creates the potential for AMR transmission through the food processing chain and into agro-ecosystems receiving the agricultural waste. Risk management includes the assessment of cost-effective methods to keep animals healthy without the need for antimicrobial use, such as the use of vaccines, nutritional supplements and pre-, pro- or synbiotics and of waste management strategies to avoid AMR transmission. Currently, there is an important gap in understanding the degree of human exposure to AMR that is generated through agriculture, the burden of illness of AMR pathogens in human populations and the relationship between exposure and burden of illness. It is important that research on the agricultural, environmental and human medicine dimensions of AMR not be undertaken in silos, which is why the United Nations and countries around the world are working together within the One Health Framework that considers the inter-relatedness of humans, animals and the environment.
\end{abstract}

\section{Affiliation}

${ }^{1}$ London Research and Development Centre, Agriculture and Agri-Food Canada, London, ON

*Correspondence: ed.topp@agr. gc.ca

Suggested citation: Topp E, Agriculture and Agri-Food Canada's research program on antimicrobial resistance. Can Commun Dis Rep. 2017;43(11):224-7. https://doi.org/10.14745/ccdr.v43i11a03

\section{Introduction}

Antimicrobial resistance (AMR) is a seminally important global public health concern and will evolve into a global public health catastrophe should predictions of pandrug resistance come to pass (1). In response to this threat, national governments, including Canada's, are developing and implementing AMR national action plans. These plans generally have four pillars: surveillance; infection control; stewardship; and innovation. Activities on these four pillars are best undertaken within the One Health Framework, recognizing the continuum between humans, animals and the environment.

\section{Context}

A key strategy for attenuating the development of AMR is ensuring judicious antimicrobial use in human medicine, veterinary medicine and agriculture. With respect to agriculture, the level of use of specific antimicrobials is highly correlated with resistance to those antimicrobials observed in generic Escherichia coli isolated from cattle, swine or poultry (2). This type of evidence clearly indicates the importance of reducing the agricultural use of antimicrobial agents, with the anticipated outcome being a reduction in the burden of bacteria that carry genes conferring AMR into the food animal production systems (3). This should reduce human exposure to pathogens (e.g., salmonella), which have acquired AMR in the food production system and to commensal bacteria, which carry AMR genes and have the potential to be mobilized into pathogens in the digestive tracts of humans.

A number of developments are underway that will result in a reduction in the use of antimicrobials in food animal production. Market pressure is driving reduced antimicrobial use; for example, consumer demand for "antibiotic-free" chicken and beef. Regulations on drug sale and use are becoming more stringent; for example, enhancement of veterinary supervision of antimicrobial use and removing the claims of the use of medically important antimicrobials for the purposes of growth promotion in food animals. Reducing antimicrobial use in food animal production represents a challenge for producers who rely on these agents to help keep their animals healthy. The specific health problems that may accompany a reduction in antimicrobial use and the desirable and effective alternative solutions to the use of antimicrobials will vary according to the commodity (i.e., poultry, swine, dairy or beef). Overall, changes in agricultural practices and the effective deployment of technologies that ensure continued animal health and wellness, quality and safety of the food products, food security and the economic prosperity of producers are foundational for a reduction in antimicrobial use in agriculture.

Agriculture and Agri-Food Canada (AAFC) is unique amongst the Canadian federal science-based departments and agencies as it has the mandate, expertise and infrastructure required 
to undertake research on all the major food animal and crop production systems. Research is undertaken in support of the overall Canadian agriculture and agri-food system, which accounts for $6.6 \%$ of the national gross domestic product and employs one in eight Canadians. For many years, AAFC's Science and Technology Branch has undertaken research on AMR in agriculture. AAFC research centres in Sherbrooke, Guelph, London, Lethbridge, Lacombe and Summerland, in particular, have active programs on dairy, swine, poultry, beef and environmental aspects of AMR.

This article provides an overview of the research being done by AAFC within three broad areas; risk assessment; risk management; and the elucidation of animal agriculture's role in AMR development and transmission and the need for international collaboration within the One Health Framework. Within the scope of this article, an antimicrobial agent is defined as a medicine that is specifically used to treat or prevent a bacterial infection, and not viral, fungal or protozoal infection.

\section{Research on AMR and agriculture}

\section{Risk assessment}

Risk assessment of AMR within the agricultural context examines the relationship between antimicrobial use and the likelihood of development of AMR in the agricultural production system. The experimental approach often compares the impact of varying antimicrobial use on the AMR burden in the gut microbiome of animals $(4,5)$. The fate of antimicrobial-resistant bacteria through the food processing chain is a key component of human exposure to these bacteria through food consumption (6). Many antimicrobial agents are excreted unchanged and thus reach the environment through manure application. Crops, including fresh produce grown in manure-fertilized ground, represent a potential route of exposure to humans or foraging animals. The ecology of antimicrobial-resistant enteric bacteria in crop production systems fertilized with manure is being investigated to assess the potential increase in AMR burden on crops at harvest $(7,8)$. The fate of antimicrobials in soil and their potential impacts on soil microorganisms is of interest $(9,10)$. Overall, the objective is to understand the dynamics of AMR development in animal and crop production systems and the potential transmission through the food processing chain into agroecosystems receiving the agricultural waste. This information can then be used to inform quantitative models that explore associations between use and resistance, quantitative human AMR microbial risk assessments and better management practices (BMPs) that reduce human exposure to antimicrobial-resistant bacteria.

\section{Risk management}

Risk management is defined here as the implementation of production practices that reduce the need for antimicrobial use, while maintaining or improving the production system's performance. The objective is to implement cost-effective methods to keep animals healthy and reduce the need for prophylactic or therapeutic use of antimicrobials (11). Options available could include vaccines, nutritional supplements, pre-, pro- or synbiotics, breeding more robust animals and improved barn design in confined production systems. Potentially the microbiomes of young animals could be optimized through inoculation (similar to fecal transplantation in humans) or through nutritional interventions that mimic the impact of growth-promoting antimicrobials on the animals. Innovations in technology and husbandry that are efficacious and cost-effective will vary according to the commodity.

An additional risk management strategy is to reduce environmental exposure to antimicrobial-resistant bacteria and antimicrobial residues that are excreted by farm animals. In some confined production practices, manure can be managed to reduce the burden of AMR prior to land application through digestion or composting (12). Fundamental and translational research in this domain has rich potential to develop and validate means of reducing agricultural antimicrobial use and thus human exposure to AMR throughout the food chain or the various environments impacted by agricultural waste.

\section{Relative significance of agriculture in development of AMR}

Determining the significance of agricultural antimicrobial use relative to other potential areas for the development and transmission of AMR to humans within the One Health Framework is a daunting task. With respect to waterborne transmission, ascribing enteric pollution from livestock vs. people in a landscape with significant populations of both human and livestock is a challenge $(13,14)$. Surveillance programs (e.g., Canadian Integrated Program for Antimicrobial Resistance or CIPARS) and various research initiatives have now generated a wealth of information on the burden of AMR in foods and in environments impacted by food animal production; however, surveillance data does not generally capture information pertaining to what happens to people once they have been exposed to antimicrobial-resistant bacteria. Hence, there is a critical gap in understanding the relationship between human exposure to AMR generated through agriculture and the overall burden of AMR pathogens in human populations. The development of methods to produce such evidence (e.g., a robust human health risk assessment) (15) would be critical to understanding the relative potential benefits of a reduction in antimicrobial use in agricultural vs. a reduction of antimicrobial use in human medicine for mitigating AMR in human pathogens.

\section{One Health Framework}

Bacteria readily circulate between people, animals and the environment. It is, therefore, important that research concerning the agricultural, environmental and human medicine dimensions of AMR not be undertaken in silos (3). As such, AAFC's research program on AMR is highly collaborative. AAFC's Science and Technology Branch overtly solicits advice from the agricultural industry and regulatory stakeholders (e.g., Veterinary Drugs Directorate of Health Canada) with respect to establishing responsible and impactful priorities for AMR research. In addition, AAFC collaborates extensively with national and international academic colleagues and with the other federal science-based departments and agencies with a stake in AMR. The Genomics Research and Development Initiative interdepartmental project on AMR (GRDI-AMR) is an excellent example of how the expertise and resources of all relevant science-based departments and agencies (AAFC, Public Health 
Agency of Canada, Canadian Food Inspection Agency, Health Canada and the National Research Council) can be leveraged for a common cause (16). The GRDI-AMR project has two overriding goals. The first goal is to gain understanding of the key activities that contribute to development of AMR in food production systems and of important exposure pathways by which AMR bacteria reach humans. This information will identify critical intervention points for mitigation. The second goal is to validate economically-sustainable technologies, practices and policies to mitigate AMR development in food production systems. This information will inform how best to manage the critical intervention points. Finally, recent position statements from the World Health Organization, the World Organisation for Animal Health and the United Nations have endorsed the One Health Framework, and these statements were recently articulated in the Pan-Canadian Framework for Action on AMR (17).

\section{Conclusion}

Antimicrobial resistance is a seminally important contemporary public health challenge. We need to use antimicrobials more judiciously and responsibly in food animal production to minimize selection for resistance and the subsequent risk of resistance transmission to humans via the food chain or the environment. The role of AAFC within the Pan-Canadian Framework for Action on AMR and antimicrobial use is to contribute to the development of innovative animal production and waste management strategies to reduce AMR in the food production system, while maintaining productivity and profitability, animal welfare, food safety and security and environmental quality. In partnership with external collaborators and stakeholders, research undertaken by AAFC will help provide Canadian farmers the tools they need to meet this challenge.

\section{Conflict of Interest}

None.

\section{Acknowledgements}

The author thanks the numerous Agriculture and Agri-Food Canada colleagues who are working towards mitigating antimicrobial resistance for the benefit of the agricultural community and all Canadians. Many thanks to C. Carson, J. Gracia-Garza, A. Lamoureux, X.-Z. Li, and R. Menassa for critically reviewing the manuscript.

\section{References}

1. O'Neill J. Tackling drug-resistant infections globally: Final report and recommendations. 2016. http://amr-review.org/ sites/default/files/160525_Final\%20paper_with\%20cover.pdf

2. Chantziaras I, Boyen F, Callens B, Dewulf J. Correlation between veterinary antimicrobial use and antimicrobial resistance in food-producing animals: a report on seven countries. J Antimicrob Chemother. 2014;69:827-34. DOI (http://dx.doi.org/10.1093/jac/dkt443). PubMed (https://
www.ncbi.nlm.nih.gov/entrez/query.fcgi?cmd=Retrieve\&db= PubMed\&list_uids=24216767\&dopt=Abstract).

3. O'Brien TF. Emergence, spread, and environmental effect of antimicrobial resistance: how use of an antimicrobial anywhere can increase resistance to any antimicrobial anywhere else. Clin Infect Dis. 2002;34:S78-S84. DOI (https://doi.org/10.1086/340244). PubMed (https://www. ncbi.nlm.nih.gov/entrez/query.fcgi?cmd=Retrieve\&db=PubM ed\&list_uids=11988877\&dopt=Abstract).

4. Diarra MS, Silversides FG, Diarrassouba F, Pritchard J, Masson L, Brousseau R, Bonnet C, Delaquis P, Bach S, Skura BJ, Topp E. Impact of feed supplementation with antimicrobial agents on growth performance of broiler chickens, Clostridium perfringens and Enterococcus counts, and antibiotic resistance phenotypes and distribution of antimicrobial resistance determinants in Escherichia coli isolates. Appl Environ Microbiol. 2007;73:6566-76. DOI (http://dx.doi.org/10.1128/ AEM.01086-07). PubMed (https://www.ncbi.nlm.nih. gov/entrez/query.fcgi?cmd=Retrieve\&db=PubMed\&list_ uids $=17827305 \&$ dopt $=$ Abstract).

5. Zaheer R, Cook SR, Klima CL, Stanford K, Alexander T, Topp E, Read RR, Mcallister TA. Effect of subtherapeutic vs. therapeutic administration of macrolides on antimicrobial resistance in Mannheimia haemolytica and enterococci isolated from beef cattle. Frontiers in Microbiology 2013;4:133. DOI (http://dx.doi.org/10.3389/ fmicb.2013.00133). PubMed (https://www.ncbi.nlm.nih. gov/entrez/query.fcgi?cmd=Retrieve\&db=PubMed\&lis t_uids=23750157\&dopt=Abstract).

6. Noyes NR, Yang X, Linke LM, Magnuson RJ, Dettenwanger A, Cook S, Geornaras I, Woerner DE, Gow SP, McAllister TA, Yang H, Ruiz J, Jones KL, Boucher CA, Morley PS, Belk KE. Resistome diversity in cattle and the environment decreases during beef production. eLife 2016;5:e13195. DOI (http://dx.doi.org/10.7554/ eLife.13195). PubMed (https://www.ncbi.nlm.nih.gov/ entrez/query.fcgi?cmd=Retrieve\&db=PubMed\&list_ uids=26952213\&dopt=Abstract).

7. Marti R, Scott A, Tien Y-C, Murray R, Sabourin L, Zhang $Y$, Topp $E$. The impact of manure fertilization on the abundance of antibiotic-resistant bacteria and frequency of detection of antibiotic resistance genes in soil, and on vegetables at harvest. Appl Environ Microbiol. 2013;79(18):5701-5709. DOI (http://dx.doi.org/10.1128/ AEM.01682-13). PubMed (https://www.ncbi.nlm.nih. gov/entrez/query.fcgi?cmd=Retrieve\&db=PubMed\&list_ uids $=23851089 \&$ dopt $=$ Abstract).

8. Marti R, Tien Y-C, Murray R, Scott A, Sabourin L, Topp E. Safely coupling livestock and crop production systems: how rapidly do antibiotic resistance genes dissipate in soil following a commercial application of swine or dairy manure? Appl Environ Microbiol. 2014;80:3258-65. DOl (http://dx.doi. org/10.1128/AEM.00231-14). PubMed (https://www.ncbi.nlm. nih.gov/entrez/query.fcgi?cmd=Retrieve\&db=PubMed\&list_ uids $=24632259 \&$ dopt=Abstract).

9. Topp E, Chapman R, Devers-Lamrani M, Hartmann A, Marti R, Martin-Laurent F, Sabourin L, Scott A, Sumarah $M$. Accelerated biodegradation of veterinary antibiotics in 
agricultural soil following long-term exposure, and isolation of a sulfamethazine-degrading Microbacterium sp. J Environ Qual. 2013;42(1):173-8. PubMed (https://www.ncbi.nlm.nih. gov/entrez/query.fcgi?cmd=Retrieve\&db=PubMed\&list_ uids $=23673752 \&$ dopt=Abstract).

10. Lau CH-F, van Engelen K, Gordon S, Renaud J, Topp E. Novel antibiotic resistance determinants from agricultural soil exposed to antibiotics widely used in human medicine and animal farming. Appl Environ Microbiol. 2017; pii:AEM.00989-17. DOI (http://dx.doi.org/10.1128/ AEM.00989-17). PubMed (https://www.ncbi.nlm.nih. gov/entrez/query.fcgi?cmd=Retrieve\&db=PubMed\&lis t_uids=28625995\&dopt=Abstract).

11. Diarra MS, Malouin F. Antibiotics in Canadian poultry productions and anticipated alternatives. Front Microbiol. 2014;5:282. DOI (http://dx.doi.org/10.3389/ fmicb.2014.00282). PubMed (https://www.ncbi.nlm.nih. gov/entrez/query.fcgi?cmd=Retrieve\& db=PubMed\&list_ uids=24987390\&dopt=Abstract).

12. Tien Y-C, Li B, Zhang T, Scott A, Murray R, Sabourin L, Marti R, Topp E. Impact of dairy manure pre-application treatment on manure composition, soil dynamics of antibiotic resistance genes, and abundance of antibioticresistance genes on vegetables at harvest. Sci Total Environ. 2017;581-582:32-9. DOl (https://doi.org/10.1016/j. scitotenv.2016.12.138). PubMed (https://www.ncbi.nlm.nih. gov/entrez/query.fcgi?cmd=Retrieve\&db=PubMed\&list_ uids=28076772\&dopt=Abstract).

13. McAllister TA, Topp E. Role of livestock in microbiological contamination of water: Commonly the blame, but not always the source. Animal Front. 2012;2(2):17-27. DOI (http://dx.doi.org/10.2527/af.2012-0039).

14. Marti R, Gannon VPJ, Jokinen C, Lanthier M, Lapen DR, Neumann NF, Ruecker NJ, Scott A, Wilkes G, Zhang Y, Topp E. Quantitative multi-year elucidation of fecal sources of waterborne pathogen contamination in the South Nation River basin using Bacteroidales microbial source tracking markers. Water Res. 2013;47:2315-24. DOI (https://doi. org/10.1016/j.watres.2013.02.009). PubMed (https://www. ncbi.nlm.nih.gov/entrez/query.fcgi?cmd=Retrieve\&db=PubM ed\&list_uids=23497974\&dopt=Abstract).

15. Ashbolt NJ, Amézquita A, Backhaus T, Borriello SP, Brandt KK, Collignon P, Coors A, Finley R, Gaze WH, Heberer T, Lawrence JR, Larsson DGJ, McEwen SA, Ryan JJ, Schönfeld J, Silley P, Snape JR, Van den Eede C, Topp E. Human health risk assessment (HHRA) for environmental development and transfer of antibiotic resistance. Environ Health Perspect 2013;121(9):993-1001. DOI (http://dx.doi. org/10.1289/ehp.1206316). PubMed (https://www.ncbi.nlm. nih.gov/entrez/query.fcgi?cmd=Retrieve $\& d b=$ PubMed $\&$ li st_uids=23838256\&dopt=Abstract).

16. Genomics Research and Development Initiative (GRDI). Shared priority projects. Ottawa (ON): Government of Canada. http://grdi-irdg.collaboration.gc.ca/eng/projects/ priority.html

17. Tackling Antimicrobial Resistance and Antimicrobial Use: A Pan-Canadian Framework for Action. https://www.canada. ca/en/health-canada/services/publications/drugs-healthproducts/tackling-antimicrobial-resistance-use-pan-canadianframework-action.html 